\title{
Identification of a 31 kDa Protein in Saccharomyces cerevisiae Whose Phosphorylation is Controlled Negatively by the CDC25 Gene Product
}

\author{
By MATTHEW L. TRIPP† AND RAMON PIÑON* \\ Department of Biology, University of California, San Diego, La Jolla, CA 92093, USA
}

(Received 5 February 1988; revised 13 May 1988)

\begin{abstract}
Phosphoprotein patterns in two mutants of Saccharomyces cerevisiae, cdc25-20(ts) and cdc2520 (ts) bcy 1 , were analysed by two-dimensional polyacrylamide gel electrophoresis. Comparison with the phosphoprotein patterns of the mutants cyrl-2(ts) and bcyl, analysed in a previous study, demonstrated not only that the $C D C 25$ gene product is a positive element in the regulation of adenylyl cyclase activity, as suggested by recent studies, but that it is also a negative element in the phosphorylation of a $31 \mathrm{kDa}$ protein ( $\mathrm{p} 31 \mathrm{c}$ and $\mathrm{p} 31 \mathrm{~d}$ ), a protein whose phosphorylation is correlated with cell cycle arrest, and dephosphorylation with cell cycle initiation, respectively. Moreover, the phosphorylation phenotype of p31c and p31d suggests that the activity of the $C D C 25$ protein is subject to feedback regulation by cAMP-dependent protein kinase, and that the $C D C 25$ protein is a key element in an ammonium $\left(\mathrm{NH}_{4}^{+}\right)$signal-response system.
\end{abstract}

\section{INTRODUCTION}

Recent genetic and biochemical studies have provided evidence that the adenylyl cyclase/ cAMP pathway in Saccharomyces cerevisiae exerts a positive control on cell cycle initiation and vegetative growth, and simultaneously a negative control over sporulation (for a review see Matsumoto et al., 1985), although the second conclusion has been challenged (Olempska-Beer \& Freese, 1987). Since the transition between vegetative growth and sporulation is normally controlled by nutritional signals, we might expect adenylyl cyclase to be the effector system to which one or more nutritional sensing systems are coupled. We have presented evidence consistent with this possibility in a recent study that showed that response to $\mathrm{NH}_{4}^{+}$is mediated by adenylyl cyclase (Tripp et al., 1986). This conclusion was based on the striking similarity in the two-dimensional gel electrophoretic pattern of phosphoproteins from $\mathrm{NH}_{4}^{+}$-starved cells and in a mutant expressing a thermosensitive adenylyl cyclase, cyrl-2(ts) (Matsumoto et al., 1984), arrested at the restrictive temperature. This analysis led us to identify several proteins whose phosphorylation was controlled positively or negatively by the cAMP pathway. Those proteins whose phosphorylation was controlled positively were found in proliferating cells, while the negatively controlled phosphoproteins appeared during cell cycle arrest, brought about by either $\mathrm{NH}_{4}^{+}$starvation or inactivation of adenylyl cyclase.

In this report we describe an extension of this type of analysis to the class II start gene, $C D C 25$ (Reed, 1980). CDC25 is of special interest since mutants that express a temperature-sensitive $C D C 25$ gene product are also derepressed for sporulation (Shilo et al., 1978), a phenotype similar to that of $c y r 1-2$ (ts) (Matsumoto et al., 1983). This result suggested that the CDC25 gene product was involved in regulating the cAMP pathway (Tripp \& Piñon, 1986). Recent complementation studies in vivo (Camonis et al., 1986; Broek et al., 1987; Robinson et al., 1987) and analysis of adenylyl cyclase activity in vitro (Daniel et al., 1987) have shown that the $C D C 25$ gene product, and more particularly its carboxy-terminal domain, is required for the $R A S$-dependent (Toda $e t$ al., 1985) regulation of adenylyl cyclase activity.

$\dagger$ Present address: Miller Brewing Company, Milwaukee, WI 53201, USA. 
Nonetheless, other observations hint at a more complex role for $C D C 25$. In contrast to the low cAMP levels of one temperature-sensitive CDC25 mutant, cdc25-5 (Camonis et al., 1986), cAMP levels were normal in another mutant, $c d c 25-1$ (Martegani et al., 1986; Portillo \& Mazon, 1986), which nevertheless remained temperature sensitive. Consistent with this phenotypic difference was the observation that although only the carboxy-terminal portion of the cloned CDC25 gene was required for complementation of the $c d c 25-5$ mutation (Camonis et al., 1986), it was not required for the complementation of the $c d c 25-1$ allele (Lisziewicz et al., 1987). Moreover, although the $b c y 1$ mutation can bypass the $R A S 1$ and $R A S 2$ requirement (Kataoka et al., 1984), it did not suppress the $c d c 25-20$ mutant (Tripp \& Piñon, 1986). In $c d c 25-1$ cells, the glucose-induced activation of adenylyl cyclase was normal at the restrictive temperature (Portillo \& Mazon, 1986), while, in contrast, no activation of adenylyl cyclase was seen in a strain with $R A S 1$ and $R A S 2$ inactivated (M. J. Mazon \& R. Piñon, unpublished results). In addition, although the $C D C 25$ product was specifically required for the glucose-induced activation of the yeast plasma membrane $\mathrm{H}^{+}$-ATPase (Portillo \& Mazon, 1986), the adenylyl cyclase/cAMP pathway was not (M. J. Mazon \& R. Piñon, unpublished results).

These various observations suggest that the $C D C 25$ gene product may have at least two functions - first, positive control over adenylyl cyclase, and secondly, positive control over cell cycle initiation by a mechanism independent of the cAMP pathway. Our objective in this study was to identify and distinguish between the different phosphoprotein pathways in which the $C D C 25$ gene product might participate by an analysis of the phosphoprotein pattern in the mutants $c d c 25-20$ (ts) and $c d c 25-20$ (ts) bcy1. Consistent with other studies, we have found that $C D C 25$ is a positive element in the regulation of adenylyl cyclase activity. However, we have also found that $C D C 25$ is a negative element in the phosphorylation of a $31 \mathrm{kDa}$ protein (p31c and p31d), identified previously (Tripp et al., 1986) as a protein whose phosphorylation and dephosphorylation is associated with cell cycle arrest and initiation, respectively. The phosphorylation phenotypes of p31c and p31d in different mutants and under different nutritional conditions are consistent with a model in which the activity of the CDC25 protein is subject to feedback regulation by the cAMP pathway. Our analysis also suggests that a $\mathrm{NH}_{4}^{+}$ nutritional sensory system is coupled to the cell division cycle regulatory mechanism via CDC25 and cAMP-dependent and cAMP-independent phosphorylation pathways.

\section{METHODS}

Yeast strains. Strains CR15-S22H [MATa cdc25-20(ts) ura3-52 trp1-289] and CR41-S2 [MATa cdc25-20(ts) bcyl ade 2 his7] were used in this study. The origin and phenotype of CR15-S22H and CR41-S2 are described in Tripp \& Piñon (1986). CR15-S22H does not complement other $c d c 25$ (ts) strains; the allele number of the mutation in CDC25 in CR15-S22H is unknown, and we denote it arbitrarily as cdc25-20. CR41-S2 is a segregant of a cross between $c d c 25$ and $b c y 1$ mutants and is considered to be a $c d c 25-20$ (ts) $b c y l$ double mutant by the following criteria: (a) when crossed to a $c d c 25$ (ts) strain, the resulting diploid is temperature sensitive, and sporulates at $34{ }^{\circ} \mathrm{C} ;(b)$ when crossed to a $b c y l$ strain, the resulting diploid is not temperature sensitive and does not sporulate.

Media and labelling conditions. Cells were grown in the low phosphate medium CM with $1 \%(\mathrm{w} / \mathrm{v})$ glucose (Tripp et al., 1986), and supplemented with uracil, adenine, tryptophan or histidine ( $40 \mu \mathrm{g} \mathrm{ml}^{-1}$ of each) as required. Noncycling medium (NCM) is CM without $\mathrm{NH}_{4} \mathrm{Cl}$. Labelling with radioactive ${ }^{32} \mathrm{PO}_{4}^{3-}$ (from ICN) was done in $\mathrm{CM}$ or NCM at $26-28^{\circ} \mathrm{C}$, or at $36^{\circ} \mathrm{C}$, as described in the Figure legends. After labelling, the cells were rapidly harvested by filtration, washed three times with $10 \mathrm{ml}$ ice-cold distilled water, and frozen at $-70^{\circ} \mathrm{C}$ until ready for breakage.

Protein extraction and two-dimensional gel electrophoresis. To each frozen pellet $400 \mu \mathrm{l}$ of breaking buffer [10 mMTris/HCl, pH 7.4, $5 \mathrm{~mm}-\mathrm{MgCl}_{2}, 1 \%$ (w/v) Nonidet P-40, $0 \cdot 1 \%$ SDS, 2 mM-phenylmethylsulphonyl fluoride, RNAase and DNAase] and a $400 \mu \mathrm{l} \mathrm{scoop} \mathrm{of} \mathrm{glass} \mathrm{beads}(0.5 \mathrm{~mm}$ diameter) was added. Each tube was vortexed at the highest setting for $90 \mathrm{~s}$, in three cycles with cooling on ice between each cycle; $50 \mu 18 \mathrm{M}$-urea was then added and the tube was vortexed for two additional cycles as before. Cell debris was removed by centrifuging in a microfuge for $5 \mathrm{~min}$, and the supernatant was lyophilized. The protein pellet was resuspended in $100 \mu \mathrm{l}$ of a solution containing $9 \cdot 5 \mathrm{M}$-urea, $2 \%(\mathrm{v} / \mathrm{v})$ Nonidet $\mathrm{P}-40,5 \%(\mathrm{v} / \mathrm{v}) 2$-mercaptoethanol, $0-5 \%(\mathrm{w} / \mathrm{v})$ ampholytes (pH 3-10), and 1\% (w/v) ampholytes (pH 5-7) and subjected to two-dimensional gel electrophoresis as described by O'Farrell (1975). Focusing in the first dimension was done by running at $400 \mathrm{~V}$ for $16-18 \mathrm{~h}$. Standard $10 \%(\mathrm{w} / \mathrm{v})$ acrylamide gels were run in the SDS dimension. After electrophoresis, the gels were fixed, stained and dried as described by O'Farrell (1975). Approximately equal amounts of protein were loaded on each gel. For all 
autoradiograms shown isoelectric focusing in the first dimension was from left (basic, $\mathrm{pH} 7 \cdot 4$ ) to right (acidic, $\mathrm{pH}$ 5.4).

\section{RESULTS}

\section{Comparison of cdc25-20(ts) and cyr1-2(ts) phosphoprotein patterns}

The phosphoprotein profile of $c d c 25-20$ (ts) cells labelled with $\left.{ }^{32} \mathrm{P}\right]$ orthophosphate at the permissive $\left(26^{\circ} \mathrm{C}\right)$ and restrictive temperature $\left(36^{\circ} \mathrm{C}\right)$ is shown in Fig. 1 . In this experiment cells were labelled at $26^{\circ} \mathrm{C}$ for $2 \mathrm{~h}$ during exponential-phase growth, while at $37^{\circ} \mathrm{C}$, cells were labelled between 2 and $4 \mathrm{~h}$ after the temperature shift. Cells labelled between 0 and $2 \mathrm{~h}$, or between 0 and $4 \mathrm{~h}$, had similar phosphoprotein patterns. By $4 \mathrm{~h}$ after a shift to $36{ }^{\circ} \mathrm{C}$, more than $90 \%$ of the $c d c 25-20(\mathrm{ts})$ cells were unbudded. Several differences in the phosphoprotein patterns between permissive and restrictive conditions are evident in Fig. 1. The majority of these differences are strikingly similar to those observed in our previous study of the mutant $c y r 1-2$ (ts) (Tripp et al., 1986) in a comparison study of proliferating and temperature-arrested cyr1-2(ts) cells. Phosphoprotein $a$ (pp31a) was found to be a major phosphoprotein in proliferating cells, but was not detected at the restrictive temperature for cyr 1-2(ts) cells. Its presence in bcyl cells under all conditions tested led us to conclude that the phosphorylation of $\mathrm{p} 31 \mathrm{a}$ is regulated positively by cAMP-dependent protein kinase. The presence of pp31a in $c d c 25-20(\mathrm{ts})$ cells at the permissive, but not at the restrictive temperature shows that the phosphorylation of $\mathrm{p} 31 \mathrm{a}$ is also regulated positively by the $C D C 25$ gene product. Phosphoprotein $b$ (pp31b), like pp31a, is phosphorylated on serine residues, and on acid hydrolysis has a phosphopeptide pattern very similar to that of pp31a, suggesting that pp31a and pp31b may be different phosphorylated forms of the same protein. The phosphorylation/dephosphorylation of both appears to be regulated coordinately (Tripp et al., 1986), but the level of phosphorylation of pp31b is always less than that of pp31a. As a result, in some autoradiographic exposures $\mathrm{pp} 31 \mathrm{~b}$ is not visualized. In some gels, small variations in the focusing range of the first electrophoretic dimension resulted in pp31a, the most basic of the phosphoproteins of interest, being excluded from the gel, and not appearing in the autoradiogram (e.g. Fig. 2B). In all such cases, repetition of the experiment or running a second gel showed that pp31a was present in vegetative medium (CM) under proliferation conditions, and in $b c y l$ cells under $\mathrm{CM}$ and $\mathrm{NCM}$ conditions.

Other phosphoproteins, for example $c, d, s$ and $z$, which were detected easily at the restrictive temperature (Fig. 1B), were, however, also major phosphoproteins in cyr $1-2$ (ts) cells at $37^{\circ} \mathrm{C}$ (Tripp et al., 1986). These proteins belong to the group of proteins whose phosphorylation is normally correlated with cell cycle arrest (Tripp et al., 1986).

Labelling time-course studies (not shown) indicated that some of the changes observed in Fig.1, for example the disappearance of pp31a or appearance of $\mathrm{pp} 31 \mathrm{c}$ and $\mathrm{pp} 31 \mathrm{~d}$, took place within $15 \mathrm{~min}$ after the temperature shift, a period which is short compared to the time required for the culture as a whole to arrest. This relatively rapid response suggests that these changes in phosphorylation may be one of the early signals leading to cell cycle arrest. These phosphorylation differences do not appear to be the result of a heat shock response, since as shown previously pp31a is readily detected in wild-type and bcyl cells after a shift to the restrictive temperature, whereas phosphoproteins $c, d, s$ and $z$ are not readily detected under the same conditions (Tripp et al., 1986).

It is important to note that in a number of cases (e.g. phosphoproteins $s, o, p$ and $q$ ) the changes in phosphorylation intensity after the shift to the restrictive temperature are not as great in $c d c 25-20$ (ts) as were seen in cyrl-2(ts) cells (Tripp et al., 1986). Possibly the difference in phosphorylation intensity of a given protein spot between the two strains may be influenced by their respective genetic backgrounds, or by differential effects of $C Y R 1$ and $C D C 25$ gene product inactivation. Nevertheless, the changes are in the same direction: for example temperature shift to the restrictive temperature resulted in increased phosphorylation of $s, o, p$ and $q$. The important result is that the major changes, disappearance of phosphoprotein $a$ and the appearance of $c$ and $d$, are the same in $c d c 25-20$ (ts) (Fig. 1) and cyr1-2(ts) (Tripp et al., 1986) upon shift to $36{ }^{\circ} \mathrm{C}$. These data taken together suggest that inactivation of the CDC25 gene 

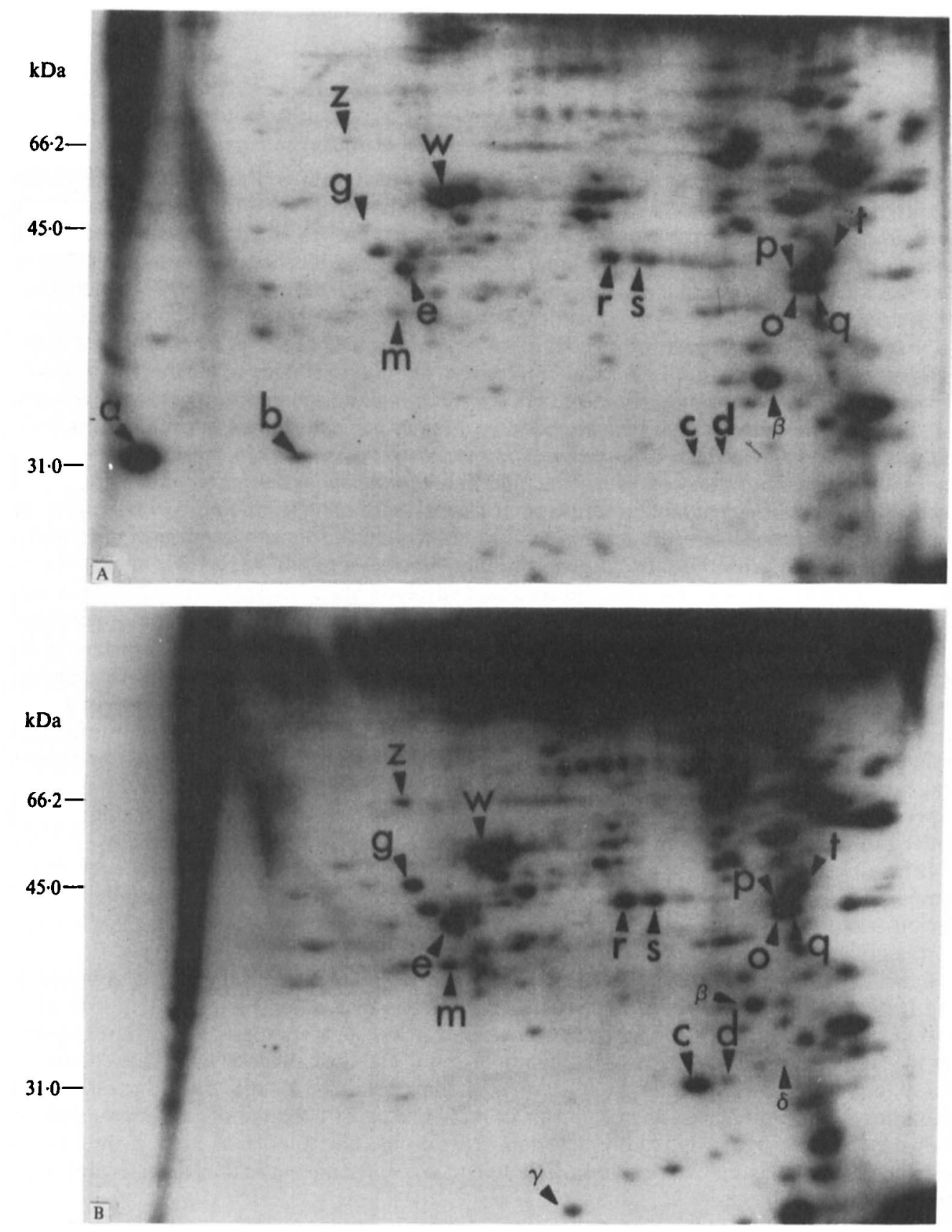

Fig. 1. Two-dimensional gel electrophoretic analysis of phosphoproteins from $c d c 25-20$ (ts) cells (strain CR15-S22H). A, Phosphoprotein pattern of exponentially growing cells at $26^{\circ} \mathrm{C}$; B, phosphoprotein pattern at $36^{\circ} \mathrm{C}$. Strain CR15-S22H was grown in $\mathrm{CM}+1 \%$ glucose at $26^{\circ} \mathrm{C}$ to a cell density of $5 \times 10^{6}$ cells $\mathrm{ml}^{-1}$. The culture was then split into two equal parts, one part remaining at $26^{\circ} \mathrm{C}$, and the other shifted to $36^{\circ} \mathrm{C}$. The $26^{\circ} \mathrm{C}$ culture was labelled with $\left[{ }^{32} \mathrm{P}\right]$ orthophosphate $\left(200 \mu \mathrm{Ci} \mathrm{m}^{-1}\right.$; $7.4 \mathrm{MBq} \mathrm{ml}^{-1}$ ) for $2 \mathrm{~h}$ while the $36^{\circ} \mathrm{C}$ culture was labelled with the same amount of $\left[{ }^{32} \mathrm{P}\right.$ lorthophosphate between 2 and $4 \mathrm{~h}$ after the temperature shift. The cells weie harvested and broken as described in Methods, and total cell proteins were extracted and resolved by two-dimensional gel electrophoresis. Approximately equal amounts of protein were loaded on each starting gel. Isoelectric focusing in the first dimension is from left (basic, pH 7.4) to right (acidic, pH 5.4). Autoradiography was done with an intensifying screen (A, $8 \mathrm{~h}$ exposure; $\mathrm{B}, 4 \mathrm{~h}$ exposure). 
product also leads to the inactivation of either adenylyl cyclase or cAMP-dependent protein kinase.

\section{Analysis of cdc25-20(ts) bcyl}

We reported previously that the $c d c 25-20(\mathrm{ts}) b c y l$ double mutant is temperature sensitive even though cAMP-dependent protein kinase activity is presumably constitutive in this mutant (Tripp \& Piñon, 1986). A phosphoprotein analysis of the double mutant would allow us to test this hypothesis more specifically, and to probe also for other cell-cycle-specific functions of $C D C 25$. We did two types of experiment with the double mutant $c d c 25-20(\mathrm{ts}) b c y 1$, a simple temperature upshift as described in Fig. 1, and a temperature upshift combined with a nutritional downshift, i.e. a CM to NCM shift. The phosphoprotein patterns in CM and NCM at the permissive and restrictive temperature for $c d c 25-20(\mathrm{ts}) b c y l$ cells are shown in Figs 2 and 3 , respectively. At a temperature permissive for $c d c 25-20(\mathrm{ts}), \mathrm{pp} 31 \mathrm{a}$ and $\mathrm{pp} 31 \mathrm{~b}$ were readily detected in the double mutant, while pp $31 \mathrm{c}$ and pp31d, although detectable, were significantly less prominent, a phenotype characteristic of $\mathrm{NH}_{4}^{+}$-depleted bcyl cells (Tripp et al., 1986). The presence of pp31a in the double mutant in NCM at both temperatures (Fig. 3A, B) indicates that the nitrogen starvation signal is being suppressed by bcyl as shown previously (Tripp et al., 1986), and biochemically confirms the bcyl genotype in strain CR41-S2. Moreover, this result indicates that the phosphorylation of $\mathrm{p} 31 \mathrm{a}$ is regulated by cAMP-dependent protein kinase, rather than directly by the $C D C 25$ gene product. Hence, the disappearance of pp31a in $c d c 25-$ 20 (ts) cells at $36^{\circ} \mathrm{C}$ (Fig. 1B), but not in cells of the double mutant $c d c 25-20$ (ts) bcyl, confirms that inactivation of the $C D C 25$ gene product normally leads to the inactivation of adenylyl cyclase.

In our previous analysis (Tripp et al., 1986) we concluded that the phosphorylation of p31c and $\mathrm{p} 31 \mathrm{~d}$ was controlled negatively by cAMP-dependent protein kinase, since pp31c and pp31d appeared following the inactivation of adenylyl cyclase, and were not seen in $b c y l$ cells. However, as seen in Figs 2 and 3, the appearance of pp31c and pp31d in $c d c 25-20(\mathrm{ts})$ bcyl cells only at the restrictive temperature for $c d c 25-20$ (ts) argues that the phosphorylation of p31c and p31d is also controlled negatively by the $C D C 25$ gene product itself.

Other phosphoprotein differences between CM and NCM conditions in the double mutant are apparent. For example, proteins $\alpha$ and $\beta$ are prominent in CR41-S2 (Fig. 2), while only $\beta$ is seen clearly in strain S22H (Fig. 1), a difference due perhaps to the presence of $b c y l$ in strain CR41-S2. Both of them respond strongly to the temperature shift in CR41-S2 in CM (Fig. 2), while $\beta$ in $\mathrm{S} 22 \mathrm{H}$ does not respond as strongly. However, both $\alpha$ and $\beta$ clearly respond to the NCM shift (Figs 2A and 3A). Hence, the phosphorylation of $\alpha$ and $\beta$ appears to depend to different extents on cAMP-dependent protein kinase, $C D C 25$ and an $\mathrm{NH}_{4}^{+}$-responsive system. Phosphoprotein $\gamma$, on the other hand, does not respond strongly to $C D C 25$ inactivation (Fig. 1), and is more prominent in CR41-S2 (Fig. 2), but does respond strongly to $\mathrm{NH}_{4}^{+}$depletion. Similarly, phosphoprotein $\delta$ appears to be regulated by $\mathrm{NH}_{4}^{+}$, but not by the $C D C 25$ gene product. These differences are consistent with our previous findings that not all phosphoprotein changes seen after a CM to NCM shift can be attributed to the adenylyl cyclase/cAMP system (Tripp et al., 1986).

\section{DISCUSSION}

Our first result (Fig. 1) shows that inactivation of the $C D C 25$ product leads to a set of phosphoprotein changes that are similar to those which occur when adenylyl cyclase is inactivated, or when cells are starved of $\mathrm{NH}_{4}^{+}$(Tripp et al., 1986), and which appear to be correlated with proliferation and cell cycle arrest. For example, p31a was identified previously as a substrate of cAMP-dependent protein kinase based on the observation that pp31a disappears when adenylyl cyclase is inactivated, and that it is always present in bcyl cells. Similarly, pp31a disappears when $c d c 25-20$ (ts) cells are shifted to the restrictive temperature (Fig. 1B). In addition, as in cyr1-2(ts) cells (Tripp et al., 1986), when $c d c 25-20$ (ts) cells are shifted to the restrictive temperature, two new major phosphoproteins, pp31c and pp31d, appear (Fig. 

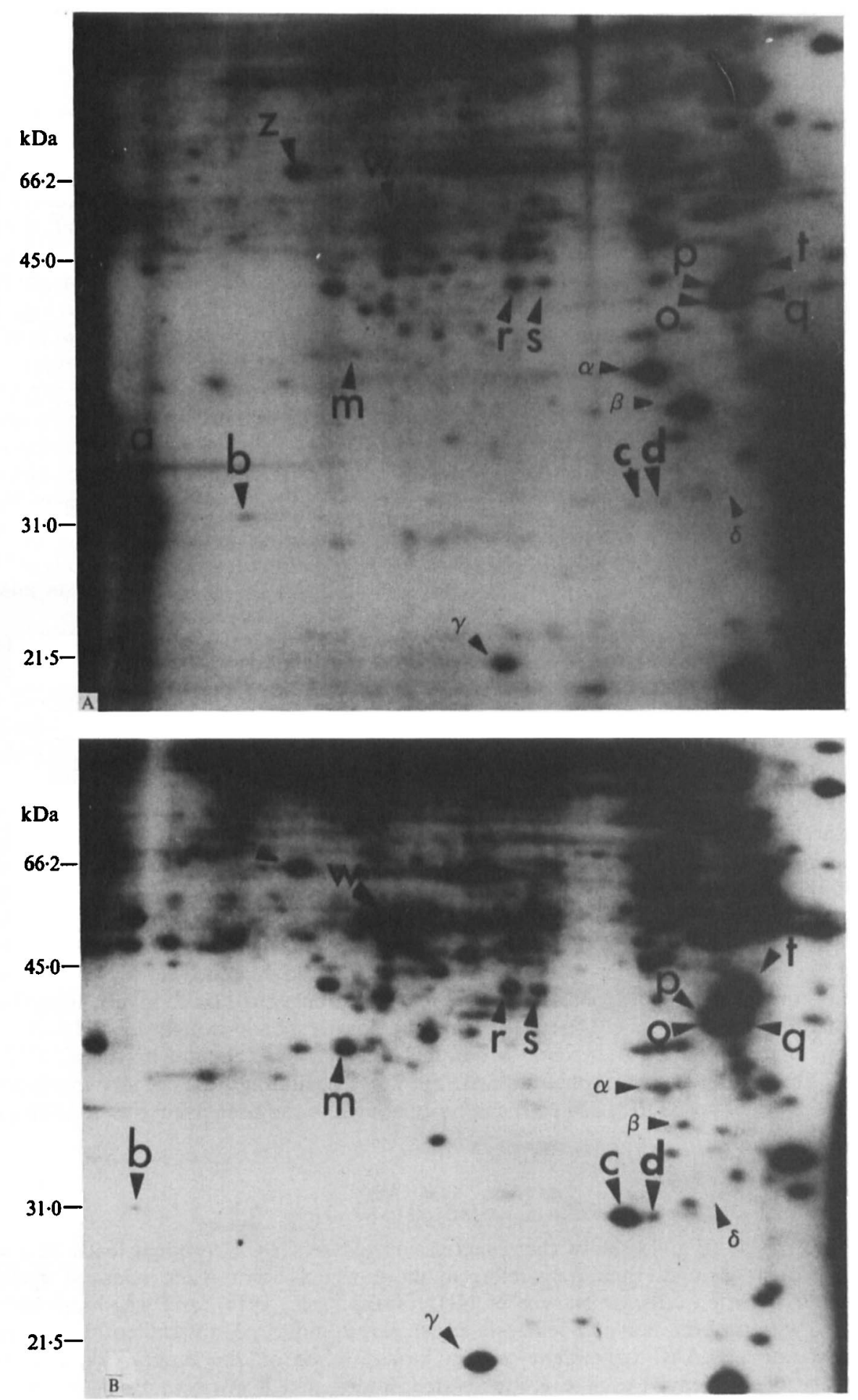

Fig. 2. Phosphoproteins from $c d c 25-20$ (ts) $b c y l$ cells (strain CR41-S2) in vegetative medium (CM). A, Phosphoprotein pattern at $26^{\circ} \mathrm{C}$; B, phosphoprotein pattern at $36^{\circ} \mathrm{C}$. Stain CR41-S2 was grown and labelled as described in the legend to Fig. 1 (A, $6 \mathrm{~h}$ exposure; B, $4 \mathrm{~h}$ exposure). 

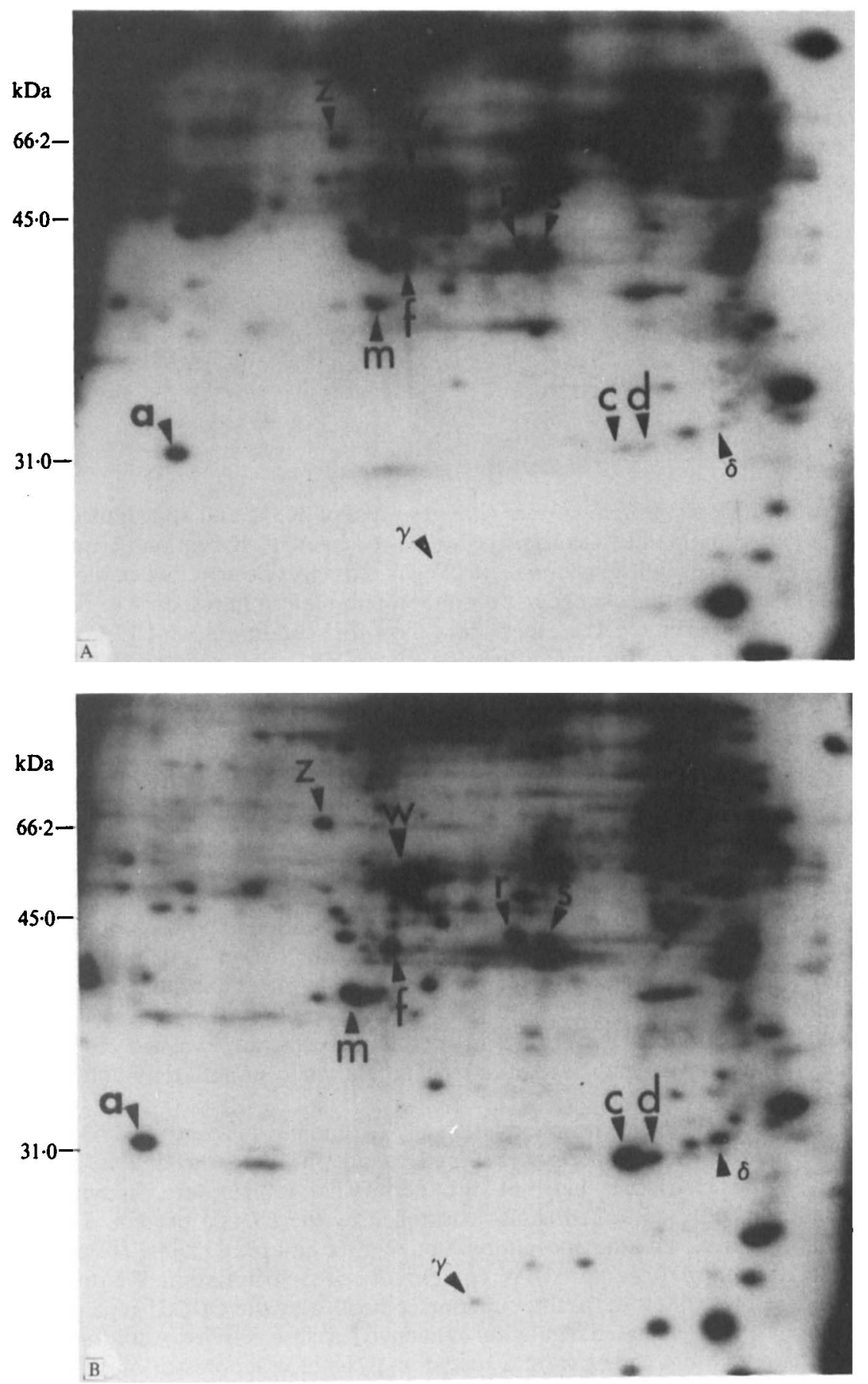

Fig. 3. Phosphoproteins from $\mathrm{NH}_{4}^{+}$-starved $c d c 25-20$ (ts) bcyl cells (strain CR41-S2). A, Phosphoprotein pattern at $26^{\circ} \mathrm{C} ; \mathrm{B}$, phosphoprotein pattern at $36^{\circ} \mathrm{C}$. Strain $\mathrm{CR} 41-\mathrm{S} 2$ was grown as described in the legend to Fig. 1. At a cell concentration of $5-6 \times 10^{6}$ cells $\mathrm{ml}^{-1}$ the culture was divided into two equal parts, both were shifted to $\mathrm{NCM}$, one incubated at $26^{\circ} \mathrm{C}$ and the other at $36^{\circ} \mathrm{C}$. After $4 \mathrm{~h}$ in $\mathrm{NCM}$, the cells were labelled for $2 \mathrm{~h}$ with [ ${ }^{32} \mathrm{P}$ ]orthophosphate $\left(120 \mu \mathrm{Ci} \mathrm{ml}^{-1} ; 4.44 \mathrm{MBq} \mathrm{ml}^{-1}\right)(\mathrm{A}, 6 \mathrm{~h}$ exposure; B, 2 h exposure). 
Table 1. Summary of phosphorylation phenotype of p31a, p31c and p31d

Data are from this study and from Tripp et al. (1986). + indicates the presence of the phosphorylated form. CM and NCM are defined in Methods. Labelling conditions are as described in this study and in Tripp et al. (1986).

\begin{tabular}{|c|c|c|c|c|}
\hline Genotype & Temperature & Medium & pp31c and pp31d & pp31a \\
\hline \multirow[t]{2}{*}{ Wild-type } & & $\mathrm{CM}$ & - & + \\
\hline & & NCM & + & - \\
\hline \multirow[t]{3}{*}{$\operatorname{cyrl} 1-2(\mathrm{ts})$} & $26^{\circ} \mathrm{C}$ & CM & - & + \\
\hline & $26^{\circ} \mathrm{C}$ & $\mathrm{NCM}$ & + & - \\
\hline & $36{ }^{\circ} \mathrm{C}$ & $\mathrm{CM}$ or $\mathrm{NCM}$ & + & - \\
\hline$b c y 1$ & & $\mathrm{CM}$ or $\mathrm{NCM}$ & - & + \\
\hline \multirow[t]{3}{*}{$c d c 25-20(\mathrm{ts})$} & $26^{\circ} \mathrm{C}$ & $\mathrm{CM}$ & - & + \\
\hline & $26^{\circ} \mathrm{C}$ & $\mathrm{NCM}$ & + & - \\
\hline & $36^{\circ} \mathrm{C}$ & $\mathrm{CM}$ or $\mathrm{NCM}$ & + & - \\
\hline \multirow[t]{2}{*}{$c d c 25-20(\mathrm{ts}) b c y 1$} & $26^{\circ} \mathrm{C}$ & $\mathrm{CM}$ or $\mathrm{NCM}$ & - & + \\
\hline & $36^{\circ} \mathrm{C}$ & $\mathrm{CM}$ or $\mathrm{NCM}$ & + & + \\
\hline
\end{tabular}

1B). These same phosphoprotein pattern changes - loss of pp31a and appearance of pp31c and pp31d - were also observed in wild-type cells arrested by $\mathrm{NH}_{4}^{+}$starvation (Tripp et al., 1986). Conversely, $b c y l$ cells, which do not undergo a regulated cell cycle arrest when subjected to $\mathrm{NH}_{4}^{+}$ starvation, did not show this change in phosphoprotein pattern in response to $\mathrm{NH}_{4}^{+}$starvation (Tripp et al., 1986). Taken together, these data show that conditions which lead to a regulated cell cycle arrest, such as inactivation of the $C D C 25$ or $C Y R l$ gene products, or $\mathrm{NH}_{4}^{+}$starvation, are correlated with changes in specific phosphoproteins. More specifically, these results suggest that the inactivation of the $C D C 25$ product leads to the inactivation of adenylyl cyclase. With respect to pp31a, the phenotype of $c d c 25-20$ (ts) bcyl at the permissive temperature is the same as that of $b c y l$ (i.e. pp31a is present under all conditions studied; Tripp et al., 1986), demonstrating that under conditions in which cAMP-dependent protein kinase is not regulated by cAMP, the phosphorylation of $\mathrm{p} 31 \mathrm{a}$ is not directly dependent on the function of $C D C 25$.

The summary of phosphorylation phenotypes (Table 1) also makes clear that although the phosphorylation and dephosphorylation of p31a appears to be correlated with proliferation and cell cycle arrest, respectively, nevertheless the dephosphorylation of pp31a is not necessary for a regulated cell cycle arrest [e.g. $c d c 25-20$ (ts) $b c y 1$ cells at the restrictive temperature; Fig. 3B]. This suggests that the conversions between $\mathrm{p} 31 \mathrm{a}$ and pp $31 \mathrm{a}$ may be secondary consequences of the mechanism that controls the transition between proliferation and cell cycle arrest. Alternatively, since pp31a is not present in sporulating cells (unpublished observations), the dephosphorylation of pp31 a may be required for sporulation [bcyl and $c d c 25-20$ (ts) $b c y l$ cells do not sporulate].

The second result is that the phosphorylation of $\mathrm{p} 31 \mathrm{c}$ and $\mathrm{p} 31 \mathrm{~d}$ is controlled negatively by the $C D C 25$ gene product. The appearance of $\mathrm{pp} 31 \mathrm{c}$ and pp31d in the double mutant $c d c 25-$ 20 (ts) $b c y l$, at the restrictive but not the permissive temperature, indicates that the phosphorylation of $\mathrm{p} 31 \mathrm{c}$ and $\mathrm{p} 31 \mathrm{~d}$ is also controlled by the CDC25 protein. The correlation between cell cycle arrest and the phosphorylation of p31c and p31d (Table 1) suggests that the dephosphorylation of pp31c and pp31d is required for cell cycle initiation. We propose that this event may define one cell-cycle-specific function controlled by the $C D C 25$ gene product that is independent of $C D C 25$-mediated regulation of adenylyl cyclase activity. Additional evidence in support of this possibility comes from a recent analysis of a suppressor of $C D C 25$ mutants, $S P R 25$, isolated and cloned in our laboratory, which shows that $S P R 25$-mediated suppression of the $c d c 25-20$ temperature-sensitive phenotype (i.e., resumption of growth at $36^{\circ} \mathrm{C}$ ) is accompanied by dephosphorylation of pp31c and pp31d (M. L. Tripp, R. Bouchard \& R. Piñon, unpublished results). We do not yet know if this event is related to another $C D C 25$-mediated process, the activation of the plasma membrane $\mathrm{H}^{+}$-ATPase (Portillo \& Mazon, 1986). In addition, we do not know if $\mathrm{p} 31 \mathrm{c}$ and $\mathrm{p} 31 \mathrm{~d}$ are different proteins, although the similarity in their 


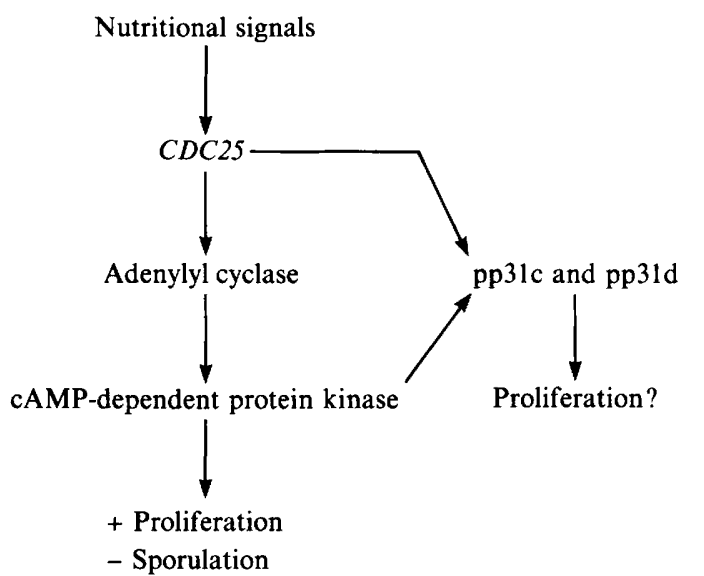

Model 1. Independent regulation of $\mathrm{pp} 31 \mathrm{c}$ and pp31d by $C D C 25$ and cAMP-dependent protein kinase

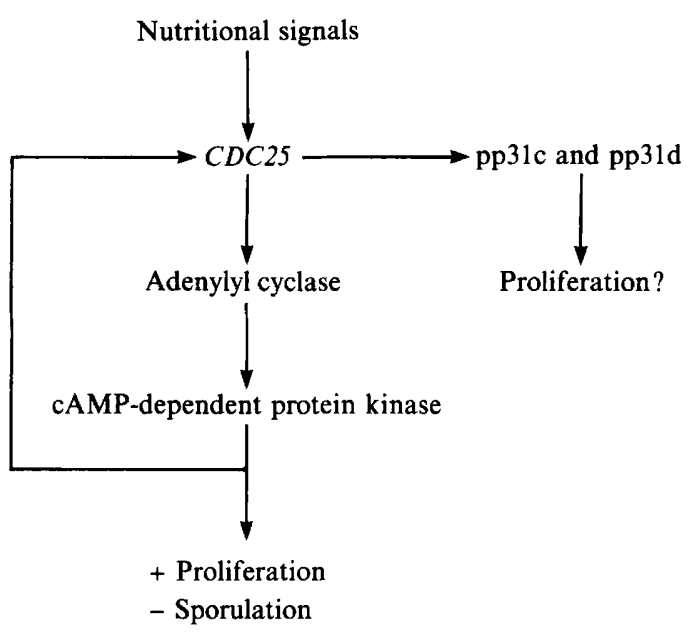

Model 2. Regulation of pp31c and pp31d by $C D C 25$ and feedback regulation of $C D C 25$ by cAMPdependent protein kinase

Fig. 4. Schematic diagram of the two models discussed in the text describing the elements involved in the regulation of p31 c and p31d phosphorylation. In model $1 \mathrm{cAMP}$-dependent protein kinase and the $C D C 25$ gene product are independently required to regulate the phosphorylation of $\mathrm{p} 31 \mathrm{c}$ and $\mathrm{p} 31 \mathrm{~d}$. In version 2 of model 2, p31c and p31d are regulated by the $C D C 25$ product, and the activity of the $C D C 25$ product is regulated by cAMP-dependent protein kinase. A causal relationship between dephosphorylation of pp31c and pp31d and cell proliferation has not yet been demonstrated.

phosphopeptide patterns after acid hydrolysis suggests that $\mathrm{p} 31 \mathrm{c}$ and $\mathrm{p} 31 \mathrm{~d}$ may be the same protein. Since both pp31c and pp31d contain phosphoserine and phosphothreonine (Tripp et al., 1986), inactivation of the $C D C 25$ protein results (presumably indirectly) in the activation of a serine-threonine-specific protein kinase, or alternatively, in the inactivation of a serinethreonine-specific protein phosphatase.

The phosphorylation phenotypes of p31c and p31d (see Table 1) also suggest two other conclusions. In the preceding paragraph, we have argued that the phosphorylation of $\mathrm{p} 31 \mathrm{c}$ and p31d is controlled negatively by the $C D C 25$ product. However, pp31c and pp31d also appear when adenylyl cyclase is inactivated, i.e. $c y r 1-2(\mathrm{ts})$ at $36^{\circ} \mathrm{C}$, and are not seen in $b c y l$ cells under any condition (Table 1). This suggests that the phosphorylation of $\mathrm{p} 31 \mathrm{c}$ and $\mathrm{p} 31 \mathrm{~d}$ is regulated negatively by both the $C D C 25$ product and cAMP-dependent protein kinase. Two different models can be proposed (see Fig. 4 for a schematic diagram).

Model 1 : regulation by the two elements is independent, for example, the phosphorylation of p31c and p3ld might be controlled by two different protein kinases, one regulated negatively by cAMP-dependent protein kinase and the other also regulated negatively by the $C D C 25$ protein. Since the $C D C 25$ gene does not appear to encode a protein kinase (Broek et al., 1987), two different mechanisms would have to be postulated to regulate the two putative protein kinases. The essential feature of this model would be that inactivation of only one element (either the $C D C 25$ product or cAMP-dependent protein kinase) would be sufficient to permit p31c and p31d to be phosphorylated.

Model 2: regulation is not independent, in which case inactivation of both elements would be required. Two different versions of this model are possible. In the first (version 1), for example, the $C D C 25$ product might independently regulate a protein kinase that is itself also controlled by cAMP-dependent protein kinase. Alternatively, the activity of the $C D C 25$ gene product itself might be under positive feedback regulation by cAMP-dependent protein kinase (version 2). Version 1 of model 2 is incompatible with the phenotype of cyrl-2(ts) cells, that is there is no 
reason to suppose that inactivation of adenylyl cyclase would also lead to the inactivation of the $C D C 25$ product. On the other hand, in the context of the known relationships between $C D C 25$ and adenylyl cyclase, the feedback version of model 2 would predict that inactivation of the $C D C 25$ product would be a consequence of adenylyl cyclase inactivation. Version 2 of model 2 can easily account for the phenotype of $c y r l-2($ ts) and bcyl as follows. In cyrl-2(ts) cells, inactivation of adenylyl cyclase would lead to the inactivation of cAMP-dependent protein kinase, which in turn would lead to the inactivation of the $C D C 25$ protein. In $b c y l$ cells, on the other hand, activity of cAMP-dependent protein kinase is constitutive, thereby maintaining the $C D C 25$ protein in an active state, and preventing the appearance of pp31c and pp31d. In the $c d c 25-20$ (ts) bcyl double mutant, pp31c and $\mathrm{pp} 31 \mathrm{~d}$ would appear only at the restrictive temperature, since inactivation of this function of the $C D C 25$ product can occur only at the restrictive temperature.

The p31c and p31d phenotype in $\mathrm{NH}_{4}^{+}$-depleted cells places another constraint on the possible models, the result of which favours the feedback version of model 2 over that of model 1 . The appearance of pp31c and pp31d in $\mathrm{NH}_{4}^{+}$-depleted wild-type cells and also in $\mathrm{NH}_{4}^{+}$-depleted $c d c 25-20$ (ts) $b c y l$ cells only at the restrictive temperature, indicates that at least with respect to the phosphorylation of $\mathrm{p} 31 \mathrm{c}$ and $\mathrm{p} 31 \mathrm{~d}$, the response to $\mathrm{NH}_{4}^{+}$-starvation is mediated by the $C D C 25$ gene product. There are two implications to this conclusion. The first is that the CDC25 gene product is either a sensor for the $\mathrm{NH}_{4}^{+}$signal or is functionally coupled to it, and that its ability to respond to the $\mathrm{NH}_{4}^{+}$signal depends on its state of activation. The second implication is that since depletion of $\mathrm{NH}_{4}^{+}$in wild type cells also leads to the appearance of pp31c and pp31d, $\mathrm{NH}_{4}^{+}$-starvation probably normally leads to the inactivation of the $C D C 25$ protein. However, since pp31c and pp31d are not seen under $\mathrm{NH}_{4}^{+}$-depletion conditions at the permissive temperature in the $c d c 25-20(\mathrm{ts}) b c y 1$ double mutant, the appearance of $\mathrm{pp} 31 \mathrm{c}$ and $\mathrm{pp} 31 \mathrm{~d}$ (presumably due to the inactivation of the $C D C 25$ product) in the normal case requires concomitant inactivation of cAMP-dependent protein kinase. This suggests that the CDC25 product and cAMP-dependent protein kinase do not act independently in the phosphorylation of $\mathrm{p} 31 \mathrm{c}$ and $\mathrm{p} 31 \mathrm{~d}$. This circumstance is most easily accommodated in the feedback version of model 2. Since the $C D C 25$ protein contains more than one consensus sequence for cAMPdependent protein kinase phosphorylation (Camonis et al., 1986; Broek et al., 1987), this requirement might mean that the $C D C 25$ protein is a direct substrate of cAMP-dependent protein kinase, or alternatively that the activity of the $C D C 25$ protein (that is, its ability to respond to the $\mathrm{NH}_{4}^{+}$signal) is modulated indirectly by cAMP-dependent protein kinase. The possibility of a feedback control system involving the $C D C 25$ protein and cAMP-dependent protein kinase has recently been suggested independently in a study of the control of cAMP levels in S. cerevisiae (Nikawa et al., 1987). Such a system of control would not be unusual. since feedback regulation of elements of signalling systems by protein phosphorylation is well documented (Sibley et al., 1987).

Hence, if the $C D C 25$ gene product were the sensor for the $\mathrm{NH}_{4}^{+}$signal or were functionally coupled to it, then (since $C D C 25$ is a positive effector of adenylyl cyclase) the absence of $\mathrm{NH}_{4}^{+}$ would lead to the inactivation of adenylyl cyclase (one function of $C D C 25$ ), and this in turn would lead to the inactivation of the $C D C 25$ product via the cAMP-dependent protein kinase feedback loop, and finally the appearance of pp31c and pp31d (the second function of CDC25). As a consequence, $\mathrm{pp} 31 \mathrm{a}, \mathrm{pp} 31 \mathrm{c}$ and pp31d would be maintained in the proper phosphorylation equilibrium in response to $\mathrm{NH}_{4}^{+}$availability. A feedback system of this type may provide an efficient way for the cell to modulate and fine-tune the activity and responsiveness of the nutritional signal response system.

We thank M. Hopkins for technical help with some of these experiments and Jeanne Lopez for help in strain construction. This work was supported by Public Health Service grant AI20388 from the National Institutes of Health, and MBRS Program grant SO6RR08135. 


\section{REFERENCES}

Broek, D., TOda, T., Michaeli, T., LeVIN, L., BirChMeIER, C., Zoller, M., PoWers, S. \& WIGLER, M. (1987). The $S$. cerevisiae CDC25 gene product regulates the RAS/adenylate cyclase pathway. Cell 48, 789-799.

Camonis, J. H., Kalekine, M., Gondri, B., Garreau, H., BOY-MARCOTTE, E. \& JAQUET, M. (1986). Characterization, cloning and sequence analysis of the CDC25 gene which controls the cyclic AMP level of Saccharomyces cerevisiae. EMBO Journal 5 , 375-380.

Daniel, J., Becker, J. M., EnARI, E. \& Levitski, A. (1987). The activation of adenylate cyclase by guanyl nucleotides in Saccharomyces cerevisiae is controlled by the CDC25 start gene product. Molecular and Cellular Biology 7, 3857-3861.

Kataoka, T., Powers, S., McGill, C., Fasano, O., Strathern, J., BROACH, J. \& WigleR, M. (1984). Genetic analysis of yeast RAS1 and RAS2 genes. Cell 37, 437-445.

Lisziewicz, J., Godany, A., Forster, H.-H. \& KuNTZEL, H. (1987). Isolation and nucleotide sequence of a Saccharomyces cerevisiae protein kinase gene that suppresses the cell cycle start mutation cdc25. Journal of Biological Chemistry 262, 25492553.

Martegani, E., Baroni, M. \& Vanoni, M. (1986). Interaction of cAMP with the CDC25-mediated step in the cell cycle of budding yeast. Experimental Cell Research 162, 544-548.

Matsumoto, K., Uno, I. \& Ishikawa, T. (1983). Initiation of meiosis in yeast mutants defective in adenylate cyclase and cyclic AMP-dependent protein kinase. Cell 32, 417-423.

Matsumoto, K., Uno, I. \& Ishikawa, T. (1984). Identification of the structural gene and nonsense alleles for adenylate cyclase in Saccharomyces cerevisiae. Journal of Bacteriology 157, 277-282.

Matsumoto, K., UNo, I. \& IshiKaWA, T. (1985). Genetic analysis of the role of cAMP in yeast. Yeast 1, 15-24.

Nikawa, J., Cameron, S., Toda, T., Ferguson, K. M. \& WIGLER, M. (1987). Rigorous feedback control of
cAMP levels in Saccharomyces cerevisiae. Genes and Development 1, 931-937.

O'FARRELL, P. H. (1975). High resolution two-dimensional electrophoresis of proteins. Journal of Biological Chemistry 250, 4007-4021.

OlempSKa-BeER, Z. \& Freese, E. (1987). Initiation of meiosis and sporulation in Saccharomyces cerevisiae does not require a decrease in cyclic AMP. Molecular and Cellular Biology 7, 2141-2147.

Portillo, F. \& Mazon, M. J. (1986). The yeast start mutant cdc 25 is defective in the activation of plasma membrane ATPase by glucose. Journal of Bacteriology 168, 1254-1257.

REED, S. I. (1980). The selection of Saccharomyces cerevisiae mutants defective in the start event of cell division. Genetics 95, 561-577.

Robinson, L. C., Gibbs, J. B., Marshall, M. S., Sigal, I. S. \& TATCHell, K. (1987). CDC25: a component of the RAS-adenylate cyclase pathway in Saccharomyces cerevisiae. Science 235, 1218-1221.

SHILO, V., SIMCHEN, G. \& SHILO, B. (1978). Initiation of meiosis in cell-cycle initiation mutants of Saccharomyces cerevisiae. Experimental Cell Research 112, 241-248.

Sibley, D., Benovic, J., Caron, M. \& Lefkowitz, R. (1987). Regulation of transmembrane signaling by receptor phosphorylation. Cell 48, 913-922.

Toda, T., UNo, I., Ishikawa, T., Powers, S., Kataoka, T., Broek, D., Cameron, S., Broach, J., Matsumoto, K. \& WigleR, M. (1985). In yeast, RAS proteins are controlling elements of adenylate cyclase. Cell 40, 27-36.

TRIPP, M. L. \& PIÑON, R. (1986). Control of the cAMP pathway by the cell cycle start function, $C D C 25$, in Saccharomyces cerevisiae. Journal of General Microbiology 132, 1143-1151.

TripP, M. L., Piñon, R., MEISENhelder, J. \& Hunter, T. (1986). Identification of phosphoproteins correlated with proliferation and cell cycle arrest in Saccharomyces cerevisiae: positive and negative regulation by cAMP-dependent protein kinase. Proceedings of the National Academy of Sciences of the United States of America 83, 5973-5977. 